\title{
Vidas educadoras: fragmentos da história das mulheres no Rio Grande do Sul
}

\author{
Clarisse Ismério ${ }^{1}$ \\ doi.org/10.47585/nemtudosaorosas6
}




\section{Introdução}

A educação feminina sofreu um grande retrocesso no período da República Velha Rio Grandense (1889-1930), pois a Doutrina Positivista reforçou a mentalidade conservadora que limitava a mulher no espaço privado e a formava para exercer as funções de esposa, mãe e educadora dos filhos. A mulher deveria ser a rainha do lar, a guardiã da moral e o anjo tutelar de sua família, sendo

[...] cuidadosamente preservada do trabalho exterior, a fim de poder preencher dignamente sua santa missão. Voluntariamente encerrada no santuário doméstico, a mulher aí promove livremente o aperfeiçoamento moral de seu esposo e de seus filhos, cujas justas homenagens ela aí dignamente recebe. (COMTE, 1988).

A mentalidade era bastante assimilada e difundida, uma vez que consideravam que a tarefa de ensinar era a grande missão da mulher, por ser o sexo afetivo, detentor da paciência cuja "missão é preparar a criança para a vida, se estivermos habilitadas a educar uma criança seremos moral e intelectualmente perfeitas e teremos cumprido o nosso destino" (ALMEIDA, 1917, p. 1).

Porém, existiram aquelas que usaram o ofício da educação para difundir seus ideais, questionar os valores tradicionais e alcançar destaque atuando como escritoras e jornalistas.

Michelle Perrot salienta que "escrever, para as mulheres, não foi coisa fácil. Sua escritura ficava restrita ao domínio privado, à correspondência ou à contabilidade”, mas também evidencia, que no final do século XIX, elas "escrevem nos jornais, nas revistas femininas. Publicam obras de educação, tratados de boas maneiras, biografias de mulheres ilustres, gênero histórico muito em voga e romances" (PERROT, 2019, p. 97). Dessa forma algumas mulheres conseguem sair do anonimato da história tradicional ao construírem suas próprias evidências.

Hilda Flores nos lembra que em decorrência do desequilíbrio social causado pelas lutas do período da Revolução Farroupilha (1835-1845), oportunizou a emancipação e produção intelectual feminina, uma vez que foi "uma escola sem precedentes, um ensaio não planejado que a apanhou de surpresa e acabou por divisar-lhe horizontes para o caminho da independência e auto realização, difícil e penosa, e ainda não culminando nos nossos dias". (FLORES, 1989, p. 19) E destaca nomes como Maria Clemência da Silveira Sampaio $^{2}$, Maria Josefa Barreto Pereira Pinto ${ }^{3}$ e Ana Eurídice Eufrosina da Fonseca de Barandas ${ }^{4}$ como representantes de um seleto grupo de intelectuais que se destacaram em âmbito nacional numa época em que grande parte da população brasileira era composta por analfabetos.

Assim quando refletirmos sobre a atuação feminina no Rio Grande do Sul Republicano, nos anos de atuação da mentalidade positivista, temos que considerar que embora a sociedade cercear-se o potencia feminino delimitando papéis e modelos, as mulheres se reinventaram ao longo de suas trajetórias de professoras e deram voz às suas aspirações e ideais que ecoaram em páginas de periódicos locais. Logo se faz necessário conhecer a algumas dessas trajetórias sob a perspectiva dos estudos feministas que:

Propicia uma atividade de escrutínio crítico, no sentido de desvendar, no quotidiano das sociedades contemporâneas, as possibilidades de áreas de resistência, de improvisação, de papéis sociais alternativos, complementares, nuançados, a descobrir outros focos de estudo, de modo a desvendar possibilidades futuras de eventuais mudanças na representação estereotipadas relações de gênero. (DIAS, 1994, p. 379).

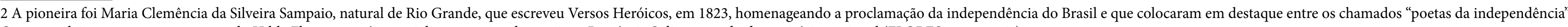
Os versos deixam transparecer, segundo Hilda Flores, o caráter social e a tentativa de engajar a Província Sulina no todo do território nacional (FLORES, 1989, p. 69).

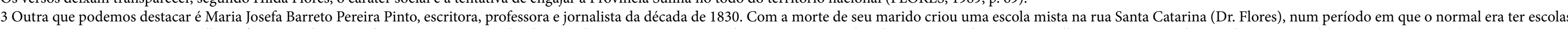
para meninos. Foi a primeira mulher a fazer jornalismo tendo o seu próprio jornal Belona irada contra os secretários de Momo, que circulou durante a Revolução Farroupilha, pois era engajada na política nacional.(FLORES, 1989, p. 69). 4 Autora de O Ramalhete, crônicas, versos e poesias que analisam os efeitos da guerra na sociedade rio-grandense (FLORES, 1989, p. 89). 
Reinventar-se e romper com os padrões tem sido o modus operandi das mulheres ao longo do tempo, cujas ações e posturas transformaram seus destinos e a sociedade onde atuaram: "As mulheres entram no espaço público e nos espaços do saber transformando inevitavelmente estes campos, recolocando as questões, questionando, colocando novas questões, transformando radicalmente" (RAGO, 2012, p. 36).

Nossa proposta foi analisar os conteúdos discursivos presentes na produção literária e jornalística das educadoras, envolvidas na trama histórica do período, que atuaram como agentes transformadores da sociedade, buscando "perceber na "outra" pesquisada uma cúmplice da descoberta de nós mesmas. [...] A pesquisa feminista identifica propositalmente a relação sujeito-sujeito como sendo o elo diferencial das demais posturas neutralizantes na pesquisa (EGGERT apud. CASTRO, 2014, p. 6)

Dessa forma, o capítulo reflete sobre algumas mulheres que atuaram como educadoras e influenciadoras de uma geração, cujos ensinamentos eram passados por intermédio de sua produção literária e jornalística.

\section{Mestres da vida}

A educação feminina esteve estreitamente ligada à relação de dominação do sexo masculino, variando conforme o modo de produção vigente, simbolismos e as representações sociais de cada período, que tornou a mulher coadjuvante da trama histórica, porque deveria se resguardar no espaço privado, cuidar do lar e da educação dos filhos. Com a legislação de 1827, foram criadas as escolas elementares femininas, onde lhes era ensinado ler, escrever, "os princípios de moral cristã e da doutrina da religião catholica e apostolica romana, [...] arithmetica só as suas quatro operações, ensinarão também as prendas que servem à economia doméstica" (Art 12 Lei de 15 de outubro de 1827).
As jovens deveriam aprender aquilo que era destinado ao seu belo sexo e o "sistema escolar brasileiro exprimia o consenso social sobre o papel da mulher. Ensinava-lhe só o que fosse necessário para viver em sociedade"(HAHNER, 2003, p.73).

No Rio Grande do Sul republicano essa mentalidade se fez presente do discurso conservador Positivista e nas normativas da tradição judaico-cristã preconizada pela Igreja Católica. Aparentemente tais instituições opunham-se frontalmente, uma vez que o primeiro possuía suas bases no discurso científico enquanto que a Igreja, em fundamentações teológicas, mas nas questões relacionadas à família, casamento, educação e moral, ambos tinham discursos muito semelhantes.

A mulher era considerada uma educadora por natureza, com isso poderia exercer a profissão de professora, orientando os alunos como se fossem seus próprios filhos. A professora trabalhava em escolas, casas particulares ou em suas próprias casas. Algumas mulheres desistiram de ser rainha do lar e de constituir família para se dedicar unicamente ao magistério. A mulher que optasse por ficar solteira era, muitas vezes, estereotipada pela sociedade, porque estaria deixando de cumprir sua função de progenitora, perdendo sua pureza espiritual, ficando desprotegida e exposta aos males da vida. Isso acontecia porque o lugar da mulher era dentro do lar cuidando de seus entes ou afazeres. Se ficasse solteira estaria fora dos padrões pré-estabelecidos, mas se decidisse dedicar-se unicamente ao magistério, ensinando as crianças como se fossem seus próprios filhos (ISMÉRIO, 2018).

$\mathrm{O}$ magistério deu destaque às mulheres nesse período, pois era o único campo em que poderiam trabalhar e exercer sua intelectualidade, como registrada por João Abbott que "na luta pela vida, sendo lhes restrito o campo de ação, buscam no magistério um lugar que não podem obter em outra profissão" (ABBOTT, 1894)

A primeira grande educadora que destacamos por romper com esse sistema é Luciana de Abreu (1847-1880), uma mulher de constituição aparentemente frágil que foi enjeitada ao nascer na 
roda dos expostos da Santa Casa de Misericórdia de Porto Alegre ${ }^{5}$, mas que se tornou gigante por meio da sua intelectualidade e liderança (Figura 1).

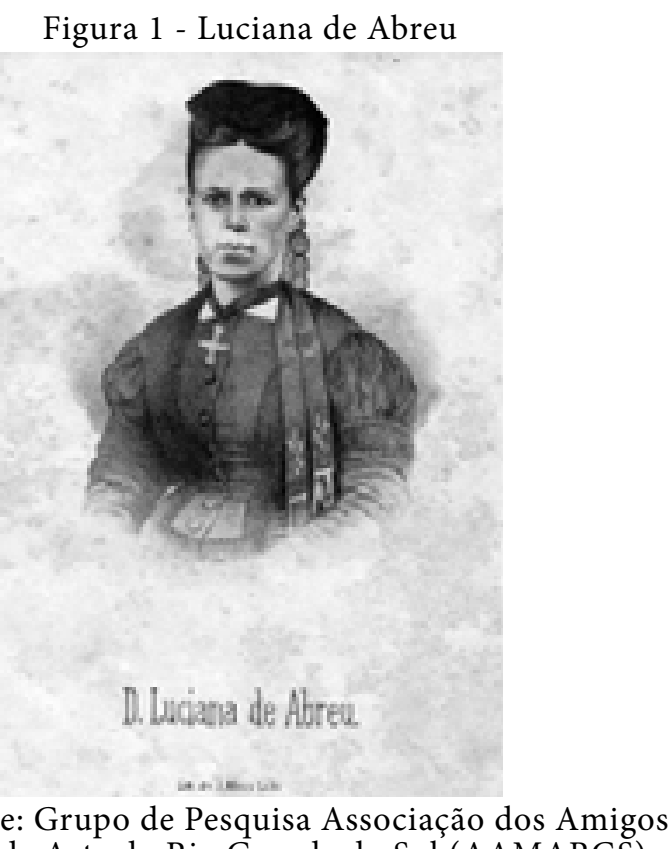

Fonte: Fonte: Grupo de Pesquisa Associação dos Amigos
do Museu de Arte do Rio Grande do Sul (AAMARGS).
Ela foi adotada pelo guarda-livros Gaspar Ferreira Viana e esposa, que dentro de suas modestas condições familiares investiram na sua educação. Desde muito jovem Luciana se dedicou intensamente aos estudos e foi a primeira aluna a se inscrever na Escola Normal da Província em $1869^{6}$, na qual obteve o título de professora em 1872 . Nesse período ela já era casada com João José Gomes de Abreu e mãe de Maria Pia, mas essa condição não foi impedimento para investir na sua profissão. Em 1873, ingressou no magistério público e em seguida criou a própria escola que possuía uma grande procura ${ }^{7}$ (MOTTA, 1987, p. 74 e FLORES, 1999, p.15). Luciana era uma mulher ímpar que conseguiu notoriedade através da educação e ao liderar a luta feminina numa sociedade pautada pelo conservadorismo patriarcal. Para Maria Josepha Pisacco Motta ela:

Desenvolveu suas capacidade intelectual até atingir a culminância que poucas mulheres de sua época conseguiram alcançar mesmo em centros mais adiantados, com maiores recursos e estímulos ao seu alcance do que certamente poderia oferecer aquela provinciana preconceituosa Porto Alegre de então. [...] Coerente com seu posicionamento de igualdade de oportunidade de ambos os sexos, soube trabalhar, vencer as dificuldades, enfrentar homen e mulheres de sua época, defender com raciocínio lúcido o seu ponto de vista, elevando-se a porta voz das reivindicações da mulher (MOTTA, 1987, p.75).

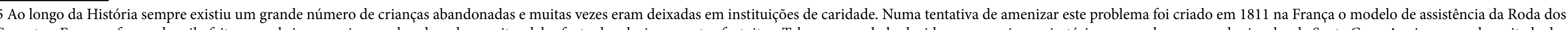

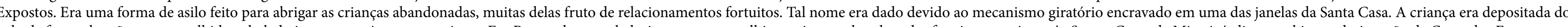

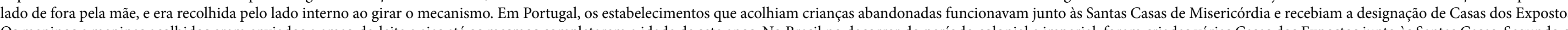

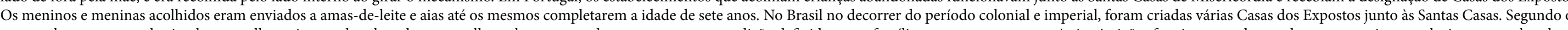

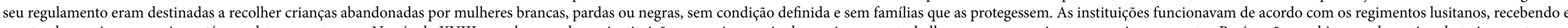

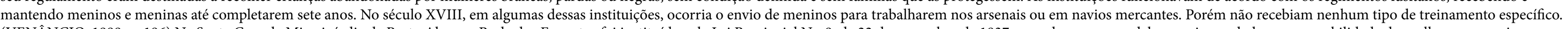

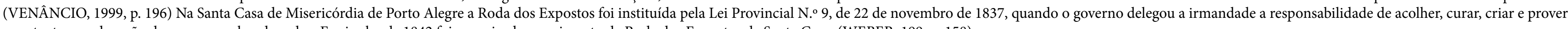
o sustento e a educação dos menores abandonados. Em junho de 1842 foi organizado o regimento da Roda dos Expostos da Santa Casa. (WEBER, 199, p. 158).

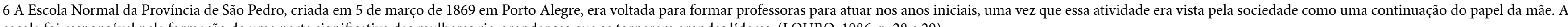
escola foi responsável pela formação de uma parte significativa das mulheres rio-grandenses que se tornaram grandes líderes. (LOURO, 1986, p. 28 e 29)
}

7 Cabe destacar que Andradina de Oliveira, que também destacamos neste capítulo, estudou na escola e foi aluna de Luciana de Abreu. 
Ao ingressar na Sociedade do Partenon Literário ${ }^{8}$ em sua primeira palestra "A Educação das Mães de Família", proferida no 6o salão literário do Partenon, deixou clara a sua luta pela igualdade entre os sexos, a partir da educação e direito ao voto.

Minhas senhoras, nós temos sido vítimas dos prejuízos das preocupações do século, nós temos sido olhadas como seres à parte na grande obra de regeneração social, quando, sem nós, impossível seria à humanidade aperfeiçoar-se e progredir. [...] Nós temos sido caluniadas, dizendo-se que somos incapazes dos grandes acontecimentos, que somos de inteligência fraca, de perspicácia mesquinha, e que não devemos passar de seres caseiros, de meros instrumentos do prazer e das conveniências do homem, quando o nosso ensino tem preparado os mais perfeitos heróis da humanidade; e quando, à testa das nações, quer na cadeira, quer na oficina modesta do operário, temos dado exemplos de assombrar os povos e os séculos! [...] O que convém pedir, o que venho aqui em vosso nome altamente reclamar, é, de parceria com a educação, a instrução superior comum a ambos os sexos; é a liberdade de esclarecer-se, de exercer as profissões a que as nossas aptidões nos levarem. Deem-nos educação e instrução: nós faremos o mais. (ABREU, 1873, p. 536-538)

A grande educadora rio-pardense Anna Aurora do Amaral Lisboa (1860-1951), ficou conhecida por sua atuação profissional e política contra Júlio de Castilhos, governador do Rio Grande do Sul de 1893 a 1898. Ana Aurora formou-se na Escola Normal em Porto Alegre em 1881, foi professora do Estado e, quando saiu do ensino público devido às divergências políticas, fundou com as irmãs, em sua cidade natal, o Colégio Amaral Lisboa. Escreveu poesias, artigos para jornais e peças de teatro, como: A culpa dos pais, Festinhas e Teatro (FLORES, 1994).
Figura 2 - A Grande Educadora, Ana Aurora do Amaral Lisboa

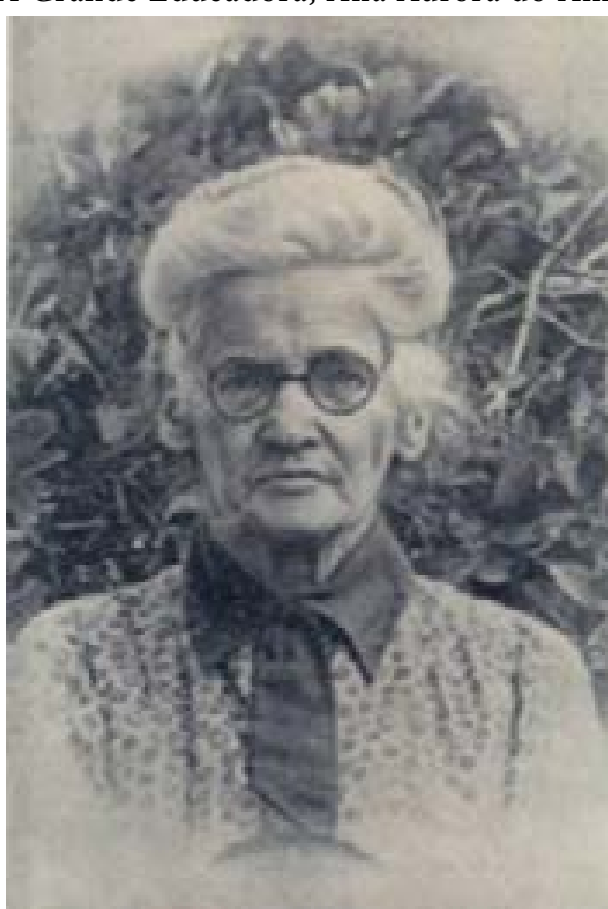

Fonte: <https://nucleopiratininga.org.br/em-22-de-marco-de-1952-falece-ana-aurora-do-amaral-lisboa/>

Ana Aurora ficou conhecida pela oposição política ferrenha a Júlio de Castilhos ${ }^{9}$ e seus seguidores, decorrente do episódio da Revolução Federalista, na qual seus irmãos foram presos pelos republicanos. Em seus escritos ela destacava a importância da atuação da mulher na política, que para tanto deveria ter uma instrução digna.

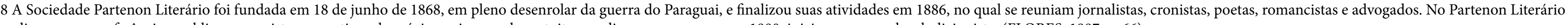
realizavam-se conferências, publicava a revista com artigos dos sócios, criou escola gratuita para livres e escravos e, em 1880, iniciou a campanha abolicionista. (FLORES, 1987, p. 66).

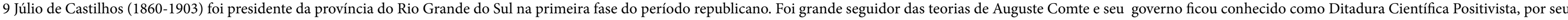
carater autoritário e conservador. 
[...] sustento quem a mulher que tem instrução e patriotismo, tem, não o direito, mas o dever de fazê-lo, mormente quando essa mulher escolheu a missão de educadora da mocidade, para essa então esse dever é imprescindível. [...] defendo o direito e sustento o dever que tem a mulher instruída, principalmente a preceptora, de tomar o mais vivo interesse pelos acontecimentos contemporâneos, como tem de estudar os acontecimentos passados da História Pátria. (LISBOA, 1895, p. 8).

Ana Aurora perdeu o pai em 1884 e desde então passou a ajudar no sustento de casa, que veio assumir por inteiro, em 1891, quando sua mãe faleceu. E junto com as irmãs fundou o Colégio Amaral Lisboa na cidade de Rio Pardo. Encontramos artigos da professora Anna Aurora publicados nos jornais e almanaques da época, sendo que especificamente no intitulado "Educação da Mulher", requer que a sociedade aceite a e uma profissão para a mulher para que não precisasse depender do sustento do homem.

Daí, pois, a vossa filha uma instrução sólida, habilitá-las, prepará-las convenientemente para que elas possam, em caso de necessidade, encarar com ânimo resoluto as vicissitudes da vida, contando com suas próprias forças e dispensando o amparo e proteção. (LISBOA, 1899, p. 108-109).

Como já foi destacado, a normatização imposta pelos positivistas era contrária ao trabalho feminino, que defendiam que a mulher deveria limitar-se ao espaço privado do lar, exercendo seus deveres de esposa e mãe, para manter a ordem natural estabelecida. Ana Aurora clama pela capacitação feminina, mas deixa claro em seu artigo que não pretende com isso a igualdade entre os sexos e muito menos, exige os mesmos direitos civis e políticos, uma vez que foi vítima do preconceito social ${ }^{10}$, sabia que não poderia mudar de uma hora para outra uma mentalidade conservadora.

Não reclamamos para o sexo a que pertencemos nenhum dos direitos civis e políticos que até aqui tem sido privilégio de outro sexo; não procuramos reivindicar a pertença igualdade de aptidões intelectuais entre o homem a mulher. Achamos, pelo contrário, que ela fica perfeitamente bem no plano secundário em que a colocaram com os preconceitos sociais. (LISBOA, 1899, p. 108).
Devido a pressão política que sofreu dos republicanos a educadora aceitou, de certa forma, a posição secundária imposta ao seu sexo; preferiu mudar a tática do seu discurso do que calar-se. Contudo em 1932, passou a compor o grupo de mulheres que participavam do movimento católico nacionalista em favor do ensino religioso, contra o divórcio e a favor dos direitos da Igreja Católica no Brasil.

As irmãs Revocata Heloísa de Mello (1858-1945) e Julieta de Melo Monteiro (1855-1828), de Rio Grande, que criaram O Corymbo, primeiro jornal feminista do Rio Grande do Sul, que circulou de 1883 a 1943, era um periódico literário que defendia os direitos sociais das mulheres (imagem 3). Elas eram filhas do negociante João Correa de Melo e da poetisa Revocata Figueiroa de Melo, sobrinhas da também poetisa Amália Monteiro e netas do jornalista português, que atuou no período Farroupilha, Manoel dos Passos Figueiroa. (FLORES,1999, p. 335).

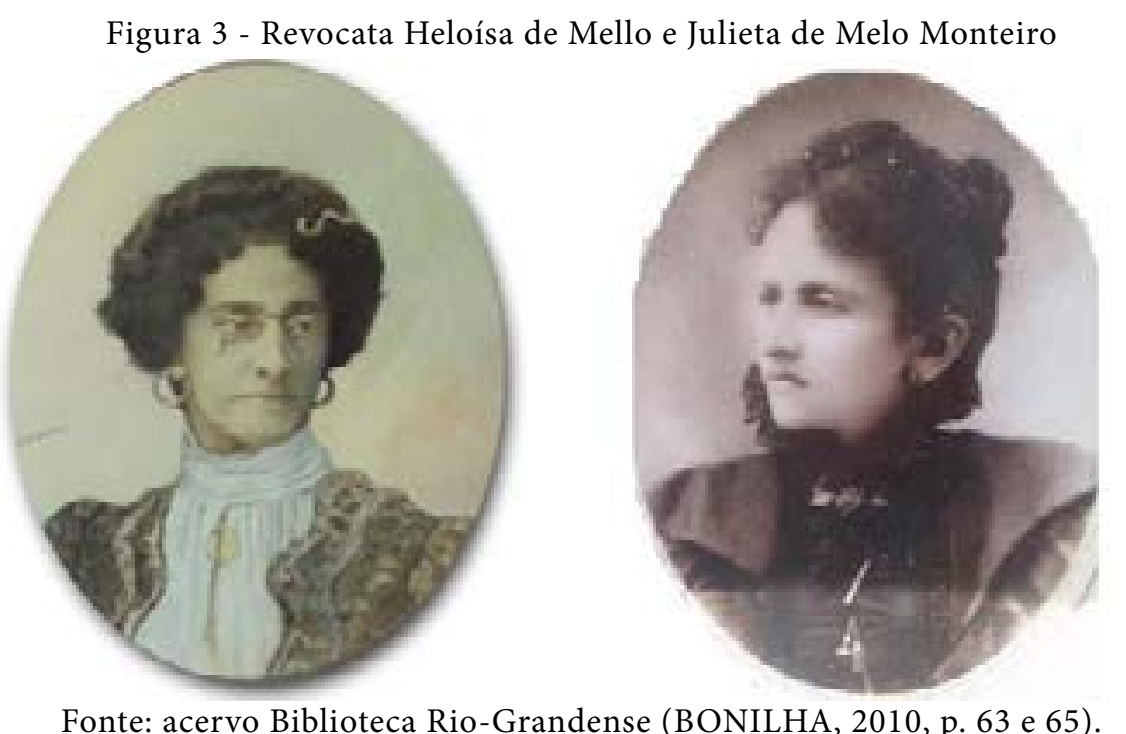

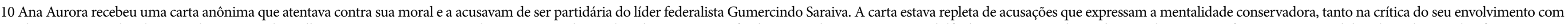

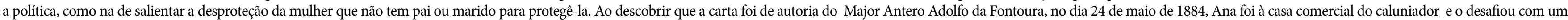
revólver. A professora sofreu um processo por este ato, mas não foi penalizada porque contou a versão do ocorrido nas páginas do jornal O Patriota. A publicação foi feita com o objetivo de sensibilizar a opinião pública. (ISMÉRIO, 2018, p. 74). 
As irmãs Mello, como eram conhecidas, também atuaram como professoras, contistas, poetisas e teatrólogas, além de colaborar com variados jornais literários da época, como

de Porto Alegre, O Lábaro (1880-1881) e O Contemporâneo (1886-1888), editados por Azevedo Júnior Revista Literária (1881), de Paulinho de Azurenha e Aurélio Veríssimo de Bittencourt. Como colaboradores dos mesmos periódicos literários, constam outros(as) escritores(as) que também publicaram no Corimbo, como Múcio Teixeira, Damasceno Vieira, Luiz Guimarães Júnior e Anna Aurora do Amaral Lisboa (Ferreira, 1975). Estavam inclúías como colaboradoras do perídicico Progresso Literário, de Pelotas e no jornal La Pátria Ilustrada, de Buenos Aires, este da propriedade de J. Guel Freire. (VIEIRA, 1997, p. 65).

Conforme Miriam Vieira (1997, p. 95), em 1890 fundaram em Rio Grande uma "escola particular em regime interno e externo" e o exercício da docência propiciou o contato com outras professoras como Ana Aurora do Amaral Lisboa e Helena Small. A autora também salienta que o Corymbo "possivelmente favoreceu a inserção das escritoras na literatura, na medida em que, além de legitimar esta atividade literária, também atuou como elemento favorável no contato com escritores e pessoas do "mundo literário". (VIEIRA, 1997, p. 94)

O Corymbo era mantido por uma rede de apoio mútuo de escritoras voltadas para o reconhecimento intelectual, qualificação da produção literária e para a luta dos direitos sociais e políticos das mulheres:

Uma das coisas engraçadas que os homens dizem, quando se lhes fala dos direitos da mulher, é que ela precisa primeiro educar-se, antes de falar em reivindicar estes pretendidos direitos.Ao mesmo tempo; quando se lhes diz que se deve cuidar a sério da educação feminina, respondem que - essa tal educação que as tornasse seres conscientes, viria, afinal, a lançá-las na vida política, e a afastá-las do lar doméstico. Não tem graça isso? (LUZ, Maria. Educação. Corimbo, nº 123, 31 de janeiro de 1919.In. VIEIRA, 1997, p.146)

E com que sarcástico desplante repetem constantemente os anti-feministas: (oh! eterna e pungente ironial Que mais querem as mulheres? Não têm elas o primeiro lugar na sociedade, não têm em tudo a primazia ... ? Aparentemente, é verdade; mas, no fundo, estas diferenças calculadas são concebidas por esmola, com a capa ignominiosa da hipocrisia, de uma humilhante magnanimidade porque dispensada ao ente considerado inferior, quando não encobrem a sutil intenção de conquista, lícita ou ilícita... (COELHO, Marianna. A principal emancipação feminina. Carimbo, n’ 77, 30 de janeiro de 1917. In. VIEIRA, 1997, p. 146)
Outra grande educadora foi Andradina América de Andrada de Oliveira, que nasceu em Porto Alegre, em 12 de julho de 1864, filha do médico sanitarista Carlos Montezuma de Andrade e de Joaquina da Silva Pacheco, natural de Rio Pardo (imagem 4). Andradina casou-se aos 17 anos com o tenente Martiniano de Oliveira (12 ${ }^{\circ}$ Batalhão de Infantaria), de origem nordestina, em $18 \mathrm{de}$ setembro de 1881, e dessa união teve os filhos Adalberon e Lola. Ao enviuvar, mudou-se com seus dois filhos para Pelotas e depois, para Rio Grande, onde contrariou os "bons costumes" e buscou o sustento da sua família. Segundo Flores, (...) a partir de sua intelectualidade: lecionou, editou livros, fez palestras e conferências remuneradas, quando se esperava da mulher que permanecesse nos afazeres do lar, na costura, nos bordados. (2007, p.11).

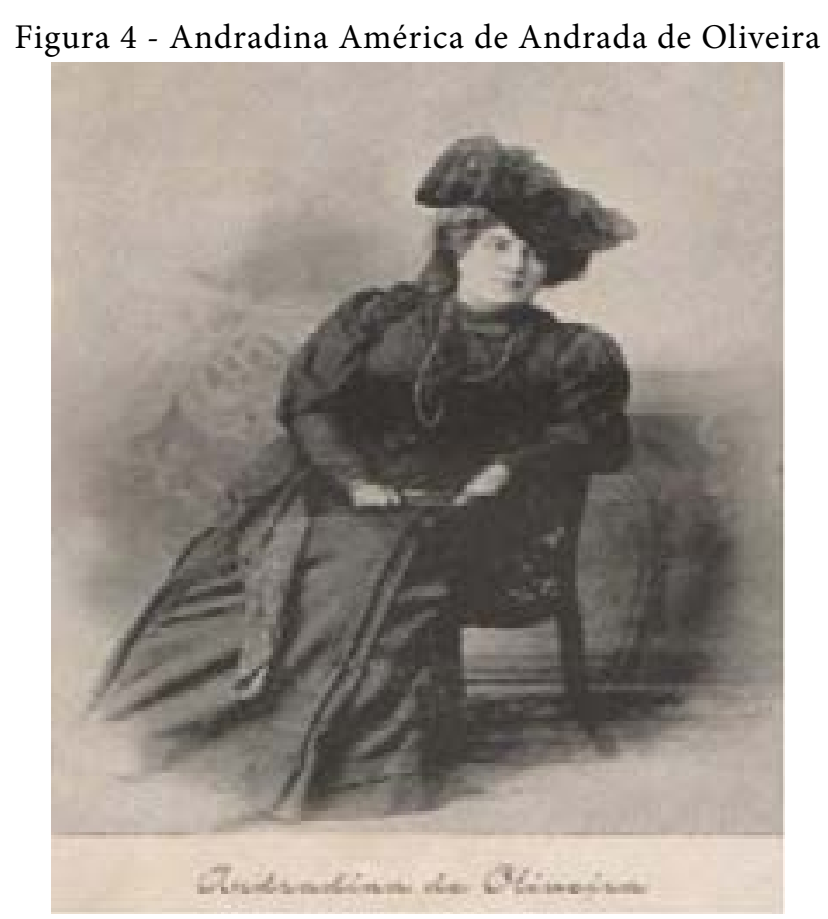

Fonte: livro Contos de natal (1908). Acervo da Biblioteca Rio-Grandense (GAUTÉRIO, 2015, p. 37). 
Em 1898, na cidade de Bagé, ela criou o Escrínio, que se tornou o segundo jornal feminista do Rio Grande do Sul, que propunha difundir o protagonismo e a emancipação intelectual feminina ao abordar os mais variados temas sociais e "será o echo de todos os bons sentimentos, de todas as legítimas e sãs doutrinas, de todas as nobres tentativas, de todos os levantados cometimentos, de todas as sublimes aspirações". (OLIVEIRA, 1898, p. 1) Andradina salienta que esse perfil editorial é resultante de suas convicções feministas:

[...] fundado por uma filha desta encantadora terra, por uma fervorosa defensora do seu sexo, o Escrínio surge, também, como um incitamento à mulher rio-grandense, convidando-a a romper o denso casulo da obscuridade, o vir à tona do jornalismo trazer as pérolas da sua cultivada intelligencia! O Escrínio aparece como um verdadeiro propagandista da instrução, do cultivo do espírito feminil! (OLIVEIRA, 1898, p. 1).

O Escrínio era um semanário que circulou de 1898 a 1910 e, a cada final de mês, tinha um número especial comemorativo dedicado às mulheres. Com a pesquisa podemos constatar que existem poucos exemplares preservados, principalmente os do período de Bagé. Observamos que apenas o número cinco encontra-se na cidade de origem, fazendo parte do acervo de jornais do Museu D. Diogo de Souza. Esse exemplar é um número especial que foi publicado no dia 30 de janeiro de 1898, cuja editora esclarece a proposta e convida aos colaboradores(as) para enviar seus escritos:

O número de hoje - o último deste mês,- como o último de todos os outros meses, será consagrado Mulher, tornando-se um número especial, pelo que pedimos aos nossos colaboradores e à pessoas que nos quiserem honrar com a gentil colaboração, sobre tão delicado tema, enviarem-nos com antecedência os originais. (OLIVEIRA, 1989, p. 2).

Nesse primeiro número especial foi composto por poemas e contos escritos por vários colaboradores, tais como Pedro Antônio de Miranda (Pelotas), Ferdinando Martino, Jáder de Carvallho, Revocata H. de
Mello, J. B. I., Leocádia Greco, Pedro Antonio de Miranda Pelotas, Ibrantina Cardona. SP, C. Reis. Elvira Gama. Rio de Janeiro, Pierrot Pelotas e J. B. I. Dentre os inúmeros elogios e aclamações as mulheres destacase as palavras da poetisa Leocádia Greco, grande amiga de Andradina, que aproveita o espaço privilegiado para expressar suas ideias sobre o papel feminino na sociedade:

Dizem que a mulher existe para criar seus filhos e cuidar dos arranjos da casa; não sendo necessário ser instruída para ser boa. Sim, diz muito bem quem vê na mulher um autômato. Imbecis! egoístas! Como melhorar as gerações si a mulher vive no obscurantismo? Como desejar um povo que compreend os deveres de cidadão se a mulher os ignora? [...] Deixemos falar os espíritos frívolos e retrógrados procuremos dissipar com o estudo a densa nuvem que nos circunda, para que a geração, que no pertence da qual somos responsáveis possa brilhar santamente com a sua luz seremos recompensados nossos esforços e abençoados pelas gerações futuras. (GRECO, 1989, p.3).

As fontes comprovam que Andradina de Oliveira foi uma mulher adiante do seu tempo, que também se notabilizou como escritora, dramaturga e conferencista ${ }^{11}$. Um de seus mais contundentes trabalhos, Divórcio?, foi escrito quando tramitava no Congresso Nacional, um novo projeto de lei que buscava a aprovação do Divórcio Absoluto, proposto por Floriano de Brito. Em seus escritos Andradina buscava sensibilizar o grande público da importância da aprovação da lei para libertar a mulher "a grande vítima dos absurdos e opressores preconceitos sociais", uma vez que mesmo estando separada do marido tinha "que se manter honesta, a despeito de tudo, mesmo na flor dos anos, seja embora só no mundo sem família, sem amparo". (OLIVEIRA, 2007, p. 27 e 30).

\section{Considerações finais}

Em nossa breve narrativa destacamos exemplos de mulheres que, num período em que a sociedade 
limitava a educação feminina preparando-as para ser a sombra dos homens, conseguiram romper as amarras e reivindicar seus direitos. As educadoras Luciana de Abreu, Aurora do Amaral Lisboa, Revocata Heloísa de Mello, Julieta de Mello Monteiro e Andradina de Oliveira quebraram o silêncio e se reinventaram.

E, como eram consideradas educadoras por natureza, utilizaram desse ofício para alçar voos mais altos e marcar espaços, por intermédio de suas produções literária e jornalísticas, para difundir seus ideais e questionar os valores da sociedade machista e conservadora que viviam. Usaram da sua escrita e do espaço privilegiado dos jornais para reivindicar uma educação digna para todas as mulheres .

Ao lermos as fontes pesquisadas buscamos reconstituir parte da trajetória de vida das educadoras que muito ensinaram no passado e ainda hoje nos edificam, pois a coragem, força e determinação dessas grandes mulheres servem como inspiração para todas nós.

\section{Referências}

ABREU, Luciana. Preleção. Revista do Parthenon Litterario, PortoAlegre, n. 12, p. 535-539, dez. 1873.

ALMEIDA, Virgínia de Castro e. A missão da Mulher. Porto Alegre: A Federação, 1917.

BONILHA, Caroline Leal. CORYMBO: Memória e representação feminina através das páginas de um periódico literário entre 1930 e 1944 no Rio Grande do Sul. Dissertação apresentada ao PPG em Memória Social e Patrimônio Cultural da Universidade Federal de Pelotas (UFPEL), 2010. Disponível em $<$ https://wp.ufpel.edu.br/ppgmp/files/2016/11/Caroline-Bonilha.pdf >. Acesso em: 5 abr. 2021.

COMTE, Auguste. Catecismo Positivista. In. COMTE. Col. Os Pensadores, São Paulo, Nova Cultural, 1988.
CASTRO, Amanda Motta. A hermenêutica Feminista como forma de análise na pesquisa científica Anais do Congresso Internacional da Faculdades EST, São Leopoldo, v. 2, 2014. Disponível em <file:///C:/Users/User/Downloads/217-1463-1-PB.pdf>. Acesso em: 13 out. 2019.

DIAS, Maria Odila Leite da Silva. Novas subjetividades na pesquisa histórica feminista: uma hermenêutica das diferenças Estudos Feminista, n. 2, 1994. Disponível em: <https://periodicos.ufsc.br/index.php/ref/article/viewFile/16219/14766> Acesso em: 11 out. 2019

FLORES, Hilda A. Hübner. Sociedade: Preconceitos e Conquistas. Porto Alegre: Nova Dimensão, 1989.

ISMÉRIO, Clarisse. Mulher: A Moral e o Imaginário 1889-1930. Bagé: EdiUrcamp, 2018.

LISBOA, Anna A. do Amaral. Educação da Mulher. In. Almanaque Popular Brasileiro, Pelotas/Rio Grande/ Porto Alegre, Ed. Echenique Irmãos e Cia/Liv. Universal, 1899.

LOURO, Guacira Lopes. Prendas e antiprendas: uma história da educação feminina no Rio Grande do Sul 1986. Tese (doutorado) -Universidade Estadual de Campinas, Faculdade de Educação, Campinas, São Paulo. Disponível em: <http://www.repositorio.unicamp.br/handle/REPOSIP/252830>. Acesso em: 4 mar. 2020.

OLIVEIRA, Andradina de. Escrínio. ano I, número 1, Rio Grande, Bagé, 2 de Janeiro de 1898. Acervo Especial da Biblioteca Nacional.

OLIVEIRA, Andradina de. Escrínio. ano I, número 5, Rio Grande, Bagé, 30 de Janeiro de 1898. Acervo Especial do Museu D. Diogo de Souza, Bagé

PERROT, Michelle. Minha História das Mulheres. 2. ed, 6. reimp. São Paulo: Contexto, 2019. 
RAGO, Margareth. Epistemologia feminista, gênero e história. Secretaria de Imprensa e Comunicação. CNTCompostela 2012. Disponível em: <http://www.cnt.gal/files/rago\%20genero\%20e\%20historia\%20web.pdf>. Acesso: 10 out. 2019.

WEBER, Beatriz Teixeira. As Artes de Curar. Santa Maria: EDUSC, 1999.

VENÂNCIO, Renato Pinto. Os Aprendizes da Guerra. In. PRIORE, Mary Del. História das Crianças. São Paulo: Contexto, 1999.

VIEIRA, Miriam Steffen. Atuação literária de escritoras do Rio Grande do Sul: um estudo do periódico Corymbo, 1885-1925. Dissertação de mestrado. Porto Alegre: Universidade Federal do Rio Grande do Sul, 1997. 